\title{
Mathematical modeling in Germany and France: a comparison of students' modeling processes
}

\section{Corinna Hankeln ${ }^{1}$ (D)}

Published online: 27 January 2020

(C) The Author(s) 2020

\begin{abstract}
The study presented in this article takes a closer look at how French and German highschool students deal with a mathematical modeling problem, what blockages they encounter and how differences in the modeling processes between students from both nations can be explained by differences between the teaching and learning of mathematical modeling in France and Germany. To better understand these differences, firstly, a brief overview is provided on the historical development of mathematics education in both countries, with a focus on mathematical modeling, followed by a qualitative empirical study in both France and Germany. Two main differences can be identified: students' handling of the real-world situation and their striving for accuracy. Possible reasons for these differences are discussed in relation to national teaching traditions.
\end{abstract}

Keywords Modeling $\cdot$ Comparative $\cdot$ France $\cdot$ Germany $\cdot$ Application

\section{Introduction}

A discussion on the integration of applications and modeling in mathematics education has taken place since the beginning of the twentieth century (see, e.g., Klein, 1907, Kühnel, 1916). Mathematical modeling is now part of many mathematics curricula all over the world (c.f. KMK, 2003, BOEN, 2015, CCSS-M, 2010). Nevertheless, each country has its own historical sociocultural background that has shaped their respective mathematics education at school. Even though the interest in international comparisons of different aspects of mathematics teaching has grown substantially in the last decades, there are few findings comparing the effects of different educational traditions in different European countries on specific mathematical activities (for proof, e.g., Knipping, 2003), and even fewer specifically on mathematical modeling.

Corinna Hankeln

c.hankeln@uni-muenster.de

1 Westfälische Universität Münster, 48149 Münster, Germany 
The study presented in this article takes a closer look at how high-school students from two different countries, Germany and France, deal with a particular mathematical modeling problem and the difficulties they encounter. As "in-depth, small-scale international comparative studies can provide unique opportunities for us to understand students' mathematical thinking" (Cai, Mok, Reddy, \& Stacey, 2017, p. 96), comparing of students from two nations with different traditions in teaching mathematics, and especially mathematics related to everyday situations, can help in generating hypotheses aimed at enhancing our understanding of why mathematical modeling is often so difficult for students. Because the study presented in this article is not based on representative data, but is collected in just one school in each country, the aim cannot be to make general statements about both countries. Nonetheless, an analysis of the relationship between students' strategies and difficulties when working on a modeling problem, and different national traditions and perspectives on mathematics, can provide insight into the complex interplay between mathematics education and students' cognitive processes. It may also help in questioning the role and value of learning aids, which were constructed in and for a specific educational context. Germany and France were chosen as examples of different traditions in teaching mathematics; on the one hand, the German teaching tradition in which mathematics is often presented and worked on with the help of contextualized problems and on the other hand the French tradition of valuing highly the strictness and precision of (pure) mathematics. Of course, these traditions are constantly being reshaped or reformed and are certainly not valid for every didactical situation in the country, but they do clearly influence how mathematics and specific mathematical problems are perceived and tackled.

\section{Theoretical background}

\subsection{Mathematical modeling}

Mathematical modeling is a topic of growing international interest (Schukajlow, Kaiser \& Stillmann, 2018). Therefore, it is not surprising that there are numerous different approaches to this field, each of them stressing different aspects (for a classification, see Kaiser \& Sriraman, 2006). The term modeling is used in this article in the following sense: "mathematical modelling always originates from a real-life problem, which is then described by a mathematical model and solved using this model. The entire process is then called modelling" (Greefrath \& Vorhölter, 2016, p. 8).

The crucial aspect of mathematical modeling is thus the transition between the extramathematical world and mathematics ${ }^{1}$ in order to solve a real-life problem. From this perspective, modeling differs from applying mathematics:

"With applications the direction (mathematics $\rightarrow$ reality) is the focus. 'Where can I use this particular piece of mathematical knowledge?' The model is already learnt and built. With mathematical modeling the reverse direction (reality $\rightarrow$ mathematics) becomes the focus. 'Where can I find some mathematics to help me with this problem?' The model has to be built through idealising, specifying and mathematising the real-world situation". (Stillman, 2012, p. 2)

\footnotetext{
${ }^{1}$ The distinction between mathematics and the rest of the world, sometimes also called the "real world", dates back to Pollak's work in 1977, where he distinguished different kinds of applications.
} 
In other words, a mathematical modeling problem is not determined by its mathematical content; rather, the mathematical content must be chosen in accordance with the real-world problem. This is of course a challenge that requires not only a sound understanding of mathematical concepts but also metacognition (Stillman, 2012) and common-sense knowledge of the real world. This contrasts with so-called dressed-up word problems, where a mathematical content is merely embellished by a context:

"Students just have to "undress" the problem by picking out the simplified real model, which is already provided in the situational description. Hence, there [note: in dressedup word problems] is no need to structure and idealize the given information or to seriously interpret and validate the mathematical results according to the real-world situation. Further, dressed up word problems do not contain superfluous or missing information. Hence, learners are not required to separate important from unimportant information or to make assumptions about missing information, requirements that are considered to be demanding characteristics of modelling problems". (Krawitz \& Schukajlow, 2018)

In this present article, modeling is considered from a cognitive perspective (Borromeo Ferri, 2006). Greefrath and Vorhölter (2016) explain that this approach is seen as a kind of metaperspective, because it is about analysing and understanding the cognitive procedures that take place in modeling problems. Not only are the different steps of problem-solving analysed, but also the students' cognitive processes. In this perspective, different descriptive models of modeling processes are developed, such as individual modeling paths that can be contrasted with the idealized modeling cycle.

In this article, the descriptive model of a modeling process, developed by Blum and Leiß (2007, see Fig. 1), is used as a basis for characterizing students' processes. This modeling cycle summarizes modeling processes in an idealized way as follows: Any modeling process starts by understanding a real situation and constructing a mental representation of the problem, the so-called situation model (Leiß, Schukajlow, Blum, Messner, \& Pekrun, 2010). This individual understanding of the situation must then be structured and simplified. This includes separating relevant from irrelevant data, searching for missing data and making assumptions. This process leads to the construction of a real model $^{2}$ which can be translated into a mathematical one, consisting of mathematical objects and language. With the help of this model and mathematical methods, mathematical results can be found, which must be interpreted in the given real-world context. Before a result can be presented, it must be validated; both the simplifications and assumptions, as well as the model and the result, must be checked for their plausibility. If the result does not seem to be satisfactory, the cycle can be run through a second time. This description of a modeling process is idealized, and research has shown that students do not strictly follow this cycle (Borromeo Ferri, 2006). Therefore, it is possible to contrast this idealized modeling process with students' individual modeling routes (Borromeo Ferri, 2010a, b), which are actual sequences of steps students undertake when solving a modeling problem. The reconstructed modeling routes can be visualized against the background of the idealized modelling cycle (ibid).

\footnotetext{
${ }^{2}$ This is called a real model, because it is still linked to the realia, the object of everyday life, whereas a conventional mathematical model is purely mathematical.
} 


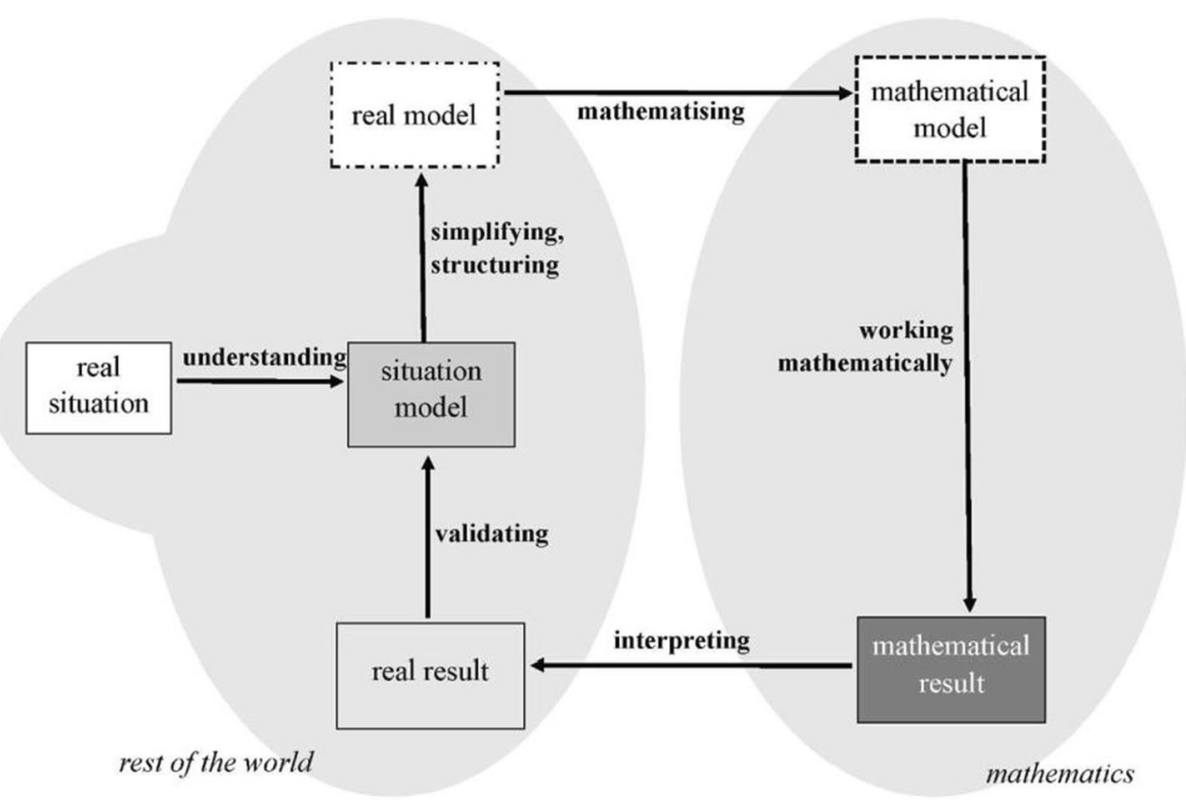

Fig. 1 Modeling cycle following Blum and Leiß (2007) (illustration as used in the analysis)

\subsection{Mathematical modeling in German and French mathematics education}

To understand the current role of modeling in mathematics education in both countries, it is important to understand how the integration of real-world problems has been shaped historically. In Germany at the beginning of the twentieth century, mathematics education in the Gymnasium ${ }^{3}$ was "dominated by elementary teaching goals, focussing on classical, Euclidean geometry and enhancing the formation of logical thinking as a key function" (Gispert \& Schubring, 2011, p. 75). Klein (1907) promoted a more utilitarian principle, which was intended to "enhance our capability for dealing with real life through a mathematical way of thinking" (Klein, 1907, p. 209, author translation). In France at that time, a similar debate about cultural versus utilitarian values of mathematics and science took place. Borel demanded as follows: "We have to introduce more life and a greater sense of reality to our mathematics education" (Borel 1904, p. 436 cited as in Gispert \& Schubring, 2011). However, Borel himself posed the question if this introduction would diminish the great educational value of secondary instruction (Borel 1904, cited as in Gispert \& Schubring, 2011). This fear of neglecting formal mathematics limited the implementation of the new program in France.

In the 1960s, radical changes in mathematics education were made in Germany, following the structuralist spirit of the epoch (Gispert \& Schubring, 2011). Since this "New Maths" movement was decided on without any consultation with mathematics educators, teachers and educators were completely unprepared. Hence, it was the textbook industry that promoted the implementation of reform decisions and "published numerous, but poor textbooks which

\footnotetext{
${ }^{3}$ The development at vocational schools (former Volksschulen) differed significantly from the Gymnasium that focused strongly on formal mathematics. Volksschulen aimed at student preparation for the upcoming aspects of their life. However, due to reform pedagogy movements, there were also changes made, for example following Kühnle's propositions for making mathematics teaching more objective and interdisciplinary and arithmetics more useful and realistic. For more information, see Greefrath \& Vorhölter (2016). In this article, the Gymnasium is focused on, as it is comparable to the French lycée.
} 
grossly exaggerated the importance of the set language" (Gispert \& Schubring, 2011, p. 95). Greefrath and Vorhölter (2016) stress that practical applications did not completely vanish during this episode but were strongly influenced by the movement. In 1975, as a consequence of public resistance against the New Maths curriculum, syllabi were changed, and the so-called New Practical Arithmetic evolved at all types of German schools. This approach aimed to integrateauthentic topics and long-term projects that were supposed to be independent of the current mathematical topic and to offer a variety of solutions. This was the beginning of the current modeling debate (Blum, 1985; Kaiser-Meßmer, 1986).

In France, the structuralist movement was not restricted to mathematics but concerned almost all school subjects. A logical presentation of different mathematical notions was promoted to eliminate everything that relied on intuition (Gispert \& Schubring, 2011). Concerning real-world applications, students were encouraged "to learn deductive reasoning methodically and to clearly differentiate the concrete world from its mathematical model" (ibid., p. 96). Even in 1975, when a new reform occurred, some orientations and choices of the New Maths movement did not disappear (ibid.). Remnants of this movement are still evident in current French mathematics education, for example in the high value placed on rigour, especially in the process of proving (Gueudet, Bueono-Ravi, Modeste \& Trouche, 2017).

At the beginning of the twenty-first century, the German educational system underwent another reform that aimed to change the scientific orientation of mathematics education, which had always emphasized rules and algorithms and highly valued formal proofs in German classrooms (Henn \& Kaiser, 2001; Kaiser, 2002). In 2003, Germany introduced national standards for mathematics education. All German federal states were to orient their school programmes towards those standards in which general mathematics competences and contentrelated fundamental ideas are formulated (KMK, 2003). These competences include mathematical modeling (KMK, 2003) with its different steps.

Despite the intensified interest in applications and modeling since the 1980s, modeling remains difficult for both German teachers and students (Blum, 2007). Especially the promotion of modeling competences is at the core of the research debate, showing clearly that modeling has to be learnt by actually doing it and that the mere inclusion of artificial and arbitrary contexts is not sufficient for developing modelling competence (Blum, 2011). However, applications in the classroom still occur mostly in the form of dressed-up word problems (Blum, 2015).

In France, in the 1990s, French mathematics education was characterized by an "encyclopaedic" (McLean, 1990), a "traditional, formal didactic style of teaching" and a "passive, authority-dependent style of learning among pupils" (Broadfoot, 1999). In 2002, a commission published a report in which they emphasized the need to connect mathematics teaching with both rigour and imagination (Kahane, 2002). This report stressed the importance of reasoning and proof and is still very influential regarding the aims and content of mathematical teaching (Gueudet, Bueno-Ravel, Modeste, \& Trouche, 2017). One of the central aims was to bring school mathematics and "live" mathematics closer, for example in mathematics laboratories, emphasizing the experimental aspect of mathematics (Kahane, 2002). Pepin (2002) notes that the traditional cours magistral (lecture type lessons) has indeed been replaced by a more dynamic view of mathematics and a more active way of constructing mathematical knowledge.

In 2015, a new curriculum was introduced in France which is organized by a set of knowledge, skills and attitudes that all students should acquire during compulsory education. Among these competences is mathematical modeling, defined as "translating a real situation into mathematical language" (BOEN, 2015) and "using mathematics to solve some problems derived from every day-situations" (BOEN, 2015). However, this curriculum does not refer to 
the different steps of the modeling cycle. This may be due to a different debate in the French mathematics education community. The French community of mathematics didactics is grounded on the fundamental idea that "each teaching and learning analysis starts from the mathematical content of what is to be learnt" (Trouche, 2017, p. 242). This contrasts with the German modeling perspective, where the mathematical content is more of a tool for solving an authentic problem than the ultimate aim of an exercise.

The above historical overview has revealed some similarities in the development of mathematics education in France and Germany. However, especially after the New Math movement, the role of applications and modeling in both countries began to differ significantly. While in France, values like rigour and precision are still very important, although now often in combination with inquiry-based learning (Grangeat, 2011). Germany continues to have a strong debate on the use of realistic applications and modeling problems in everyday teaching and in examinations (Greefrath, 2011).

\section{Research questions}

The above explanations have shown that mathematical modeling is now part of mathematics curricula both in France and Germany. However, both countries have a different tradition of classroom culture concerning the use of real-world problems. Since student resource choices for answering questions are influenced by their desire for precision, or contentment with estimates, arising from what is emphasized, and the teaching approach in the different cultures (Molyneux-Hodgsons, Rojano, Sutherland, \& Ursini, 811,999, p. 175), it is probable that the different traditions in both countries are related to differences concerning students' modelling processes, for example the choice of models, handling of inaccuracy or of superfluous data. This study attempts to answer the following research questions:

(1) What do the individual modeling routes of German and French students look like, and what blockages do they encounter?

(2) Are there recurring differences between the modeling routes of the German and French students or the blockages they encounter?

Additionally, these differences will be discussed against the background of the different teaching traditions concerning the integration of real-world contexts in the two countries. Moyer, Robison and Cai (2018) have already shown that students' attitudes are likely to be related to the use of different curricula; this could also be valid for students' blockages in a modeling process because different curricula and teaching traditions also imply different opportunities to learn for the students.

\section{Methods}

To answer these questions, a qualitative study was conducted in France and in Germany, in which several types of information were gathered. Firstly, regular maths lessons for three classes of one school in each country (from the French lycée or the German Gymnasium) were videotaped. Secondly, individual modeling processes of 18 French and 12 German students from these classes were filmed in a laboratory-like setting, using think-aloud methods, and 
thirdly, the respective teachers were interviewed about their mathematical views and their knowledge of or attitudes towards mathematical modeling. These studies were accompanied by an analysis of the respective national curricula and a choice of mathematics textbooks. This article focuses on a comparison of the individual modeling processes and of the difficulties that students encountered.

The sample was drawn from grade 10 to 12 students who had already been schooled in the respective systems for a relatively long period. Students in a higher grade already have a larger set of mathematical tools at their disposal to activate for their modeling processes than students of a younger age. The schools that volunteered to participate were both located in a comparable socio-economic surrounding in Nantes (France) and near Münster (Germany).

In both schools, the data were collected similarly. The students who volunteered to participate were seated in a separate room, alone with the researcher whom they already knew from previous observations. Students were introduced to the think-aloud method by watching a short video of the researcher solving a sudoku puzzle where she articulated every thought. Afterwards, the students were asked to continue the same puzzle, also thinking out loud in their native language, to practice the methods. Directly after this exercise, they were given the actual modeling task and asked to work on the problem and again to express every thought out loud. The researcher was seated next to the respective student and listened to the propositions without interfering. She only intervened if the student seemed to be completely at a standstill. In those cases, she gave the student some prepared hints. Even though these hints were constructed as strategic aids in relation to the modelling cycle, they made no actual references to it, as the cycle was not known to the students. When students stated that they had completed their work, they were asked if they were satisfied with their result, which sometimes led to a continuation of the modelling process. In the last $5 \mathrm{~min}$ of each of the 45-min sessions, a short interview with the students took place about their own perceptions of their modelling process (e.g., "Do you find the problem difficult?", "Why or Why not?" or "Do you know such problems from school?").

The French and German transcriptions of these studies were evaluated following the principles of qualitative content analysis (Mayring \& Fenzl, 2014) using the modeling cycle by Blum and Leiß (2007) as analytical tool to reconstruct the individual modeling processes. This method had already been successfully used by several scholars (Borromeo Ferri, 2010a, b; Schukajlow, 2006). Student processes were divided into sequences corresponding to the phases of the modeling cycle (e.g., understanding as construction of a situation model, structuring and simplifying as construction of a real model, etc.). These sequences were coded using the definition of modeling activities by Maaß (2006) (see Table 1). About $25 \%$ of the transcripts were coded by a second, independent rater. The inter-rater reliability (Cohen's Kappa) was with $\kappa=0.82$ in a satisfactory range.

These analyses permitted an in-depth-reconstruction of the students' individual modeling routes, as well as an identification of students' blockages and deviations in comparison to the idealized modeling cycle. According to the framework by Galbraith and Stillman (2006), a blockage was identified when a student encountered an obstacle in his solution process, for example when he or she did not know how to proceed, when he or she did not construct an adequate model/result and thus had to go back to a previous step of the modeling cycle. This framework was chosen as it had already been employed in previous studies (Stillman, Brown, \& Galbraith, 2010; Schaap, Vos, \& Goedhart, 2011). Nevertheless, it should be kept in mind that it is usual not to follow the 
Table 1 Coding categories following Maaß (2006)

\begin{tabular}{|c|c|}
\hline Category & The student is... \\
\hline Understanding & $\begin{array}{l}\text {...reading or repeating the problem; building a mental representation of the situation } \\
\text { without knowingly simplifying it }\end{array}$ \\
\hline $\begin{array}{l}\text { Structuring and } \\
\text { simplifying }\end{array}$ & $\begin{array}{l}\text {...making assumptions for the problem and simplifying the situation; recognizing } \\
\text { quantities that influence the situation, naming them and identifying key variables; } \\
\text { constructing relations between the variables or looking for available information or } \\
\text { differentiating between relevant and irrelevant information }\end{array}$ \\
\hline Mathematizing & $\begin{array}{l}\text {...mathematizing relevant quantities and their relations; choosing appropriate mathematical } \\
\text { notations and representing situations graphically }\end{array}$ \\
\hline $\begin{array}{l}\text { Working } \\
\text { mathematically }\end{array}$ & $\begin{array}{l}\text {.. using heuristic strategies such as a division of the problem into part problems, } \\
\text { establishing relations to similar or analogous problems, rephrasing the problem, viewing } \\
\text { the problem in a different form, varying the quantities or the available data, etc.; using } \\
\text { mathematical knowledge to solve the problem }\end{array}$ \\
\hline Interpreting & $\begin{array}{l}\text {...interpreting mathematical results in extra-mathematical contexts; viewing solutions to a } \\
\text { problem by using appropriate mathematical language and/or communicating about the } \\
\text { solutions }\end{array}$ \\
\hline Validating & $\begin{array}{l}\text {...critically checking and reflecting on solutions found; reviewing some parts of the model } \\
\text { or again going through the modeling process, if solutions do not fit the situation; } \\
\text { reflecting on other ways of solving the problem or whether solutions can be developed } \\
\text { differently; generally questioning the model }\end{array}$ \\
\hline
\end{tabular}

modeling cycle strictly and that good modelers may also jump back and forth within it. Therefore, the number of deviations cannot be interpreted as an indicator of student abilities, but the nature and reasons for such deviations do yield insight into students' thought processes. To answer the research questions, the modeling processes of students from one country were compared to each other; frequent blockages were identified and compared between the two countries.

Students worked on an adapted version of the lighthouse task (Borromeo Ferri, 2010a, b) (see Fig. 2). Students are asked to find the distance between a ship and a lighthouse, when the ship observes the light for the first time. The task contains both superfluous information, like the lighthouse being originally planned to measure $50 \mathrm{~m}$, but also missing information, like the radius of the earth.

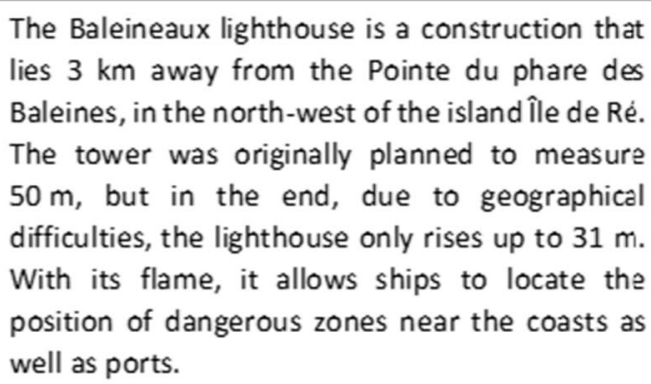

What distance to the coast does a ship still have when it catches sight of the lighthouse's light for the first time?

https://upload.wikimedia.org/wikipedia/commons/3/31/Baleineaux.jpg

Fig. 2 The Lighthouse Task (an adaptation of the task used in Borromeo Ferri 2010a, b) 
The task can be solved by different means, for example by a simple application of the Pythagorean theorem, if one neglects the height of the ship and approximates the curved distance between the ship and the lighthouse by a straight line, or by trigonometric calculations, if one wants to calculate the length of the curved distance (see the appendix). This task was chosen, as it had already been tested in empirical studies (Borromeo Ferri, 2006, 2010a, b), can be solved by a broad range of models and requires considerations both on the realworld and on the mathematical side of the modeling cycle.

\section{Findings}

The analysis revealed both similarities and differences between modeling processes by German and French students. First, it was evident that none of the students were familiar with this kind of open modeling problem, which required a deep understanding of the real-world situation. Nevertheless, the different episodes of their working processes could be categorized according to the modeling cycle of Blum and Leiß (2007) (see Table 1). For the students, one of the most difficult steps in finding a solution was to acknowledge the essential role of the earth's curvature. This blockage could be observed in both countries. However, some aspects could be found that differed systematically between both countries. Table 2 gives an overview of some blockages that occurred in the students' modeling processes. Even though these numbers should not be overinterpreted due to the small, non-representative study, it is noticeable that the German students in the sample often reflected upon the real-world situation rather superficially and quickly tried to find a mathematical representation. By contrast, the French students were hindered more by the underdetermination of the task and commented on their dissatisfaction with the only approximate result.

As it is necessary for international comparative studies to provide in-depth evidence of student thinking and reasoning (Cai et al., 2017), the qualitative analysis of modeling processes from a German and a French student will be presented below. Even though they are of course just individual examples, these students were chosen because they demonstrate typical aspects that could be found in several student processes from the same country.

Table 2 Blockages and models in the modeling processes

\begin{tabular}{|c|c|c|}
\hline Blockages in the modeling process & $\begin{array}{l}\text { Germany } \\
(n=12)\end{array}$ & $\begin{array}{l}\text { France } \\
(n=18)\end{array}$ \\
\hline Difficulties with underdetermination of the task & $25 \%$ & $44 \%$ \\
\hline Difficulties with overdetermination of the task & $25 \%$ & $22 \%$ \\
\hline Dissatisfaction with imprecision & $0 \%$ & $22 \%$ \\
\hline Wrong representation of the situation (top view) & $16 \%$ & $33 \%$ \\
\hline Difficulties with integrating the earth's curvature in the model & $33 \%$ & $5 \%$ \\
\hline Superficial consideration of the real-world situation & $33 \%$ & $0 \%$ \\
\hline False assumptions & $8 \%$ & $28 \%$ \\
\hline Difficulties in the calculation & $33 \%$ & $16 \%$ \\
\hline Mathematical models used in the modeling process & $\begin{array}{l}\text { Germany } \\
(n=12)\end{array}$ & $\begin{array}{l}\text { France } \\
(n=18)\end{array}$ \\
\hline Mathematical model: Pythagorean theorem & $75 \%$ & $50 \%$ \\
\hline Mathematical model: sine/cosine & $25 \%$ & $50 \%$ \\
\hline
\end{tabular}




\subsection{Timothé}

Timothé is a French student from Seconde (approx. Grade 10). He starts his modeling process by trying to construct a real model but struggles with the overdetermination of the task (like $22 \%$ of the French students). He has difficulties understanding the task and is unsure which information might be helpful. He misunderstands the text, thinking that the lighthouse was originally planned to shine up to $3 \mathrm{~km}$ (which is the distance to the coast), but that now, with only $31 \mathrm{~m}$ height instead of $50 \mathrm{~m}$, this distance has shortened (see Fig. 3a). When he understands which distance is required, his spontaneous reaction is that "You can't know that, because you don't know the light's interval." He explains that he would like to solve the task with a scale conversion, but that some information is missing. His blockage no longer originates in the overdetermination of the task but in its underdetermination. He states several times: "I can't solve it, because there is information missing." This reaction could be found in $44 \%$ of the French cases. The researcher encourages Timothé to change perspective and asks, "If you imagine you are standing on top of the lighthouse, how far can you see the ships?" Timothé answers, "Up to where they pass... for example, here, that's the globe, there is the lighthouse, a bit big, and the boat, and here it becomes smaller, here you see it much smaller and here you don't see it anymore. But you can't know it, you don't know the horizon!" (see Fig. 3b). At this point, Timothé's blockages change from understanding the problem and constructing a real model to finding a mathematical model to calculate the distance to the horizon. He calculates the earth's circumference and starts looking for the angle between the lighthouse and the boat (see Fig. 3c). First, he proposes a sketch to scale but quickly realizes that the differences in length between the radius and the lighthouse are too big for this approach. He draws another sketch of the situation (see Fig. 3c) and comes up with the idea of using an additional triangle in his model. At this point, Timothé is determined to calculate the length of the arc. However, since he does not remember trigonometric formulas, he contents himself with calculating the length of the ray of light ( $\mathrm{x}$ in Fig. 3c). The last phase of his modeling process focuses on finding and criticizing the result. Timothé finds a length of $19.8 \mathrm{~km}$, but he is, like $22 \%$ of the French students, not satisfied with this solution: "Yes, 19,8 km, except that it is not the solution, it's an exception, if the ray of light is there and given the fact that it is lower here... ((points at the curvature of the globe))." Timothé knows he has not found an exact result but just an approximation. However, Timothé is not able to pursue this approach further.

Figure 4 summarizes Timothé's individual modeling route. It is evident that most leaps forwards and backwards occur between the construction of a real and a mathematical model. There are two massive interventions by the interviewer (arrows 5 and 7) where Timothé is asked to rethink the
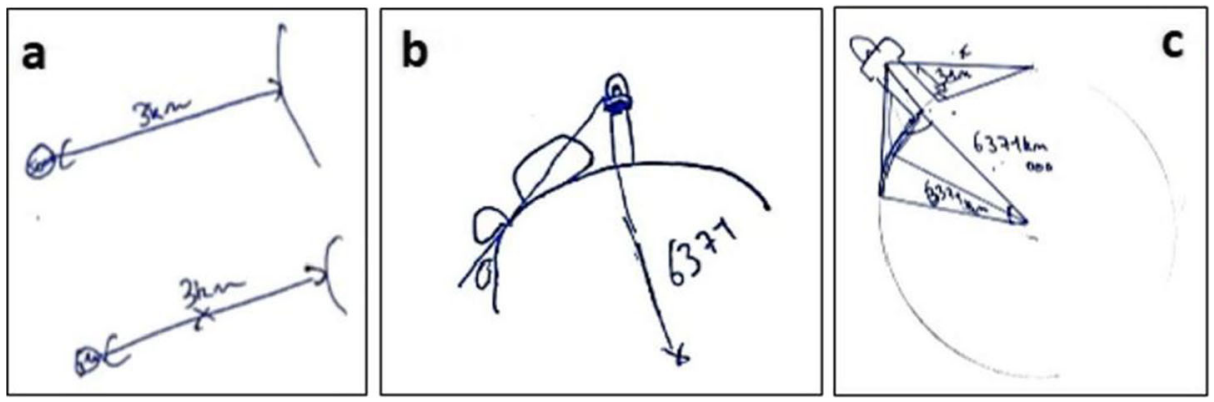

Fig. 3 Timothé's sketches: a the smaller lighthouse does not shine $3 \mathrm{~km}$. b The ship disappears behind the horizon. c Identification of mathematical objects in the real model 


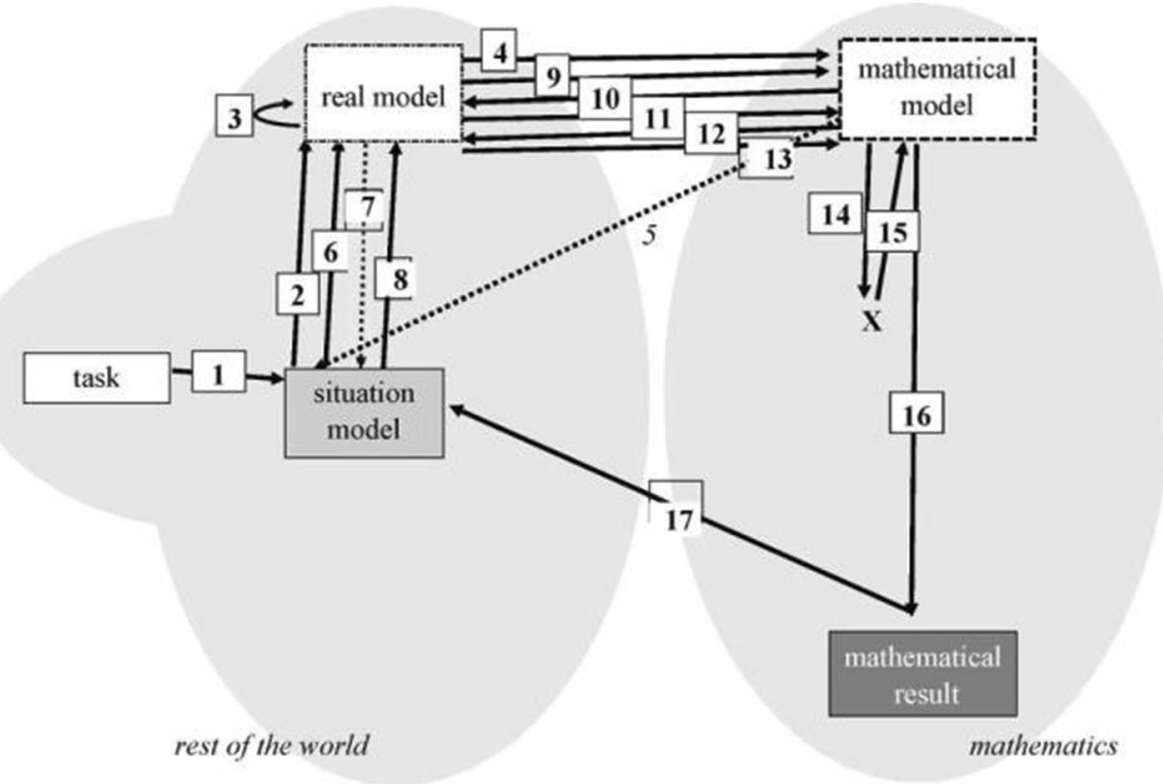

Fig. 4 Timothé's route through the modeling cycle. [Dotted arrows: Interviewer's intervention]

situation and to revise his situation model. The " $\mathrm{X}$ " between arrows 14 and 15 shows his failure in working with his first mathematical model (calculation of the angle at the centre of the earth).

\subsection{Marie}

Timothé's modeling process can be compared to the work of Marie, a German grade 12 student. After reading the exercise, she begins by drawing a sketch of the situation (Fig. 5a) but quickly tries to transform the given task into a mathematical problem by reducing the situation to a simple triangle (Fig. 5b). This approach is rather typical, as it can be found in $33 \%$ of the German cases.

Marie proposes to use the Pythagorean theorem but remarks that there are two (unknown) variables. Consequently, she is not able to use her proposed model. When she is asked what limits the maximum distance of the light, Marie names the distance between ship and lighthouse $\mathrm{x}$ and concludes: "Theoretically, this could be as big as possible. That would be the circumference, as big as possible, 'till it comes back, once around the world." She expresses this thought in a formalized way and notes " $x \rightarrow$ earth". She even illustrates the
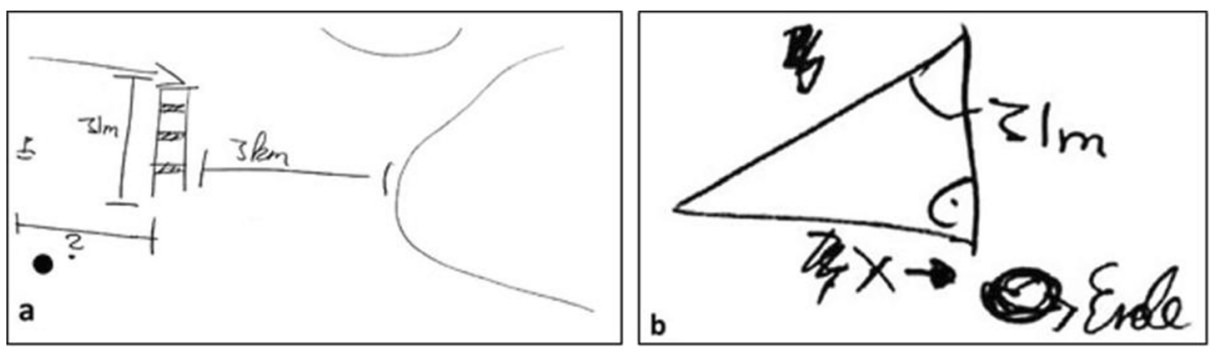

Fig. 5 Marie's sketches: a Marie's real-model. b Marie's first attempt at a mathematical model 
assumption that the light shines around the globe in another sketch (Fig. 6a) and explains "theoretically, that would be the longest, that will not be the case, because light does not shine so far, but if you assume that it does... ." Such a false assumption is not typical of the German students in the sample, occurring only in $8 \%$ of the cases. More typically, German students tried to mathematize the situation overhastily and did not bother to even make assumptions.

Only when Marie is asked if the lighthouse can be seen from the other side of the world, she answers 'No, that is on the other side, if you've got a sphere, you don't see what's on the other side, you can't look through." When asked what restricts the maximum distance, Marie explains "That depends... first you have to start from the idea that the weather is good, but since this is a modeling task and in maths it is always like that, that you start from the idea that there is clear visibility and everything's perfect and so on."

Like $33 \%$ of the German students, Marie struggles with integrating the earth's curvature into her mathematical model. After she is given the hint to draw a side view and include the earth's radius of $6371 \mathrm{~km}$, her first attempt is to blindly use the earth's radius as the X-value. When this attempt fails, she starts to look for "a second triangle that can be placed somewhere in here, to calculate the distance." After a while, she gets the idea of using a mathematical model like that in Fig. 6b. After some time, she identifies a right angle in her drawing. However, she is not able to justify why there must be such an angle, except that this would allow her to use the Pythagorean theorem. She finds a value for the triangle's side that she named "?" (Fig. 6b). She uses this value and again the Pythagorean theorem to find a solution $(x=19,87 \mathrm{~km})$. She interprets this result as the distance between the lighthouse and the ship and concludes, "You have to determine the distance between the ship and the coast [..] you've got to add $3 \mathrm{~km}$." Marie does not spontaneously see a need to validate her result. When asked, she states that she is satisfied with her result just because she has found an answer and is able to retrace her thought process. Like all of the German students, she readily accepts the imprecision of the result. In response to the question of whether her result seems to be plausible, she answers, "I would say so, well it's pretty far, but in our holidays, we are often at the North Sea and there is a lighthouse as well and if we want to go there by car, we need almost an hour to get there, but from the beach though, we can see it all the time."

Figure 7 depicts Marie's individual modeling route. The similarities to Timothé's route are evident. Marie, just like Timothé, works mostly on the first modeling steps, even though her frequent attempts to mathematize the problem are clear. These attempts fail twice (after arrows 4 and 11). Like Timothé, Marie has to be asked to rethink previous steps of her modeling process by the interviewer (arrows five and eight).
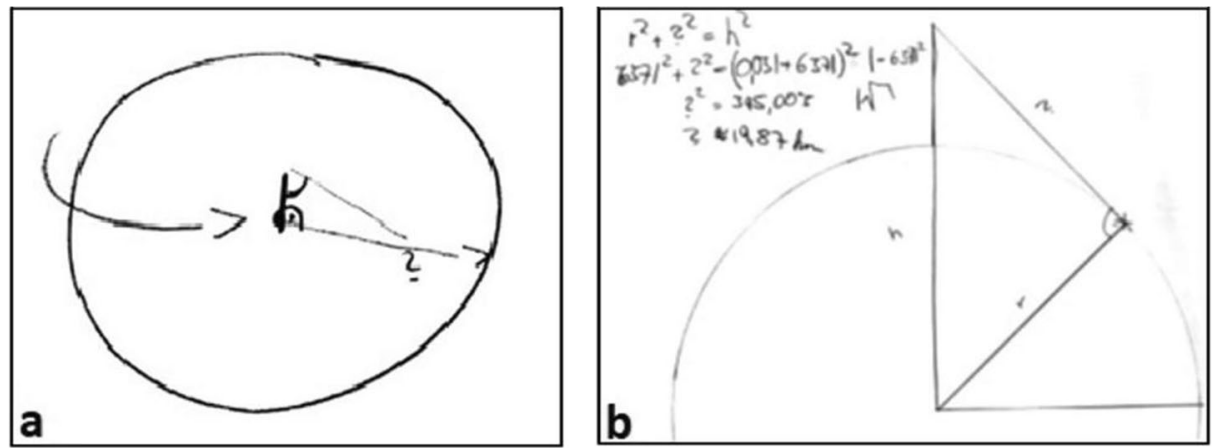

Fig. 6 Marie's sketches: a the light going around the globe. b Marie's final mathematical model 


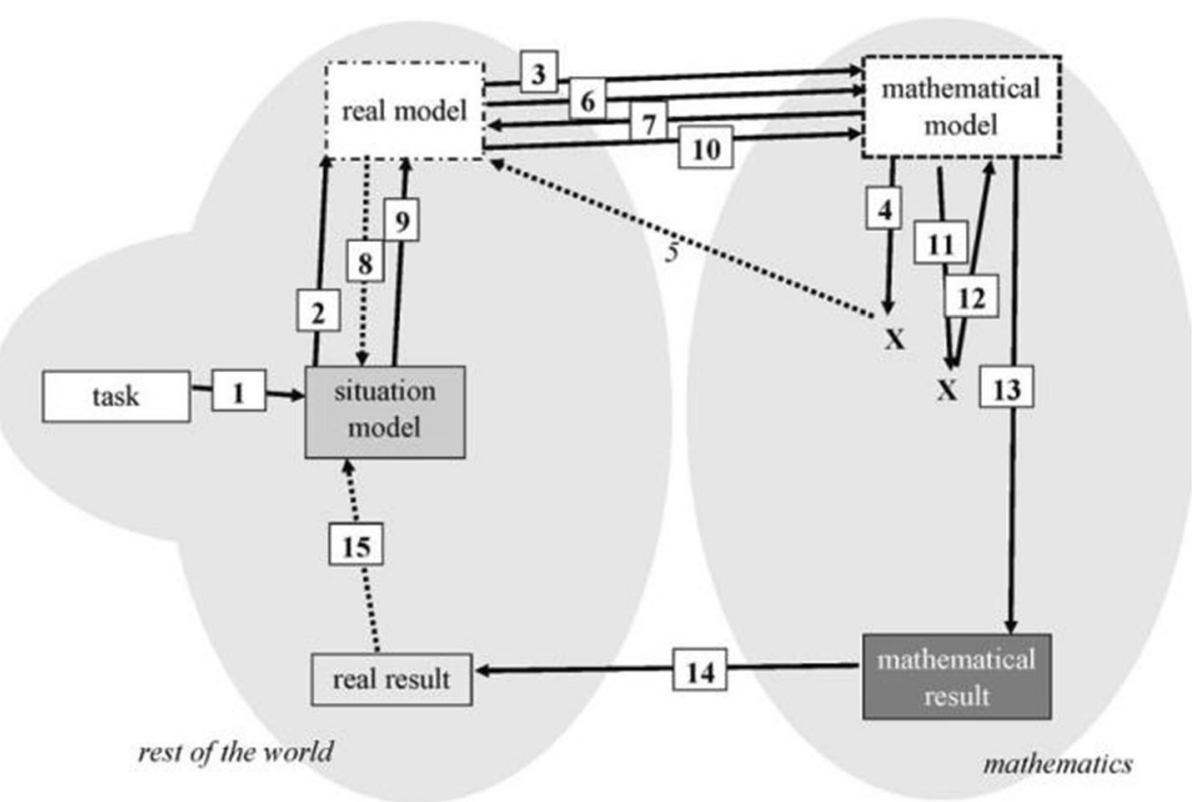

Fig. 7 Marie's route through the modeling cycle. [Dotted arrows: Interviewer's intervention]

\subsection{Comparison of both students}

As the descriptions of these cases show, both students follow their own path through the modeling cycle. Nevertheless, there are some basic differences in their approaches. The first concerns their handling of the real-world situation. At the beginning, Timothe has difficulties in understanding the aim of the task. After his modeling process, he explains: "The most difficult part was to put myself in this place, because I kept thinking that there was something missing and that I couldn't find it, but you just had to base your work on the real facts, there is nothing like this in maths." He is not used to the need to activate extra-mathematical knowledge to solve a mathematics problem. His frequent protests that the task cannot be solved show his difficulties in disengaging himself from a rigid and formalized view of procedures that can be applied to a mathematical problem. He struggles both with the over- and the underdetermination of the task. Marie has less difficulty in identifying what is relevant for her solution, because she seems to be used to idealized situations. She does not attempt to obtain a deep understanding of the situation but quickly tries to transform the task into a mathematical problem. This becomes especially evident when she uses the earth's circumference as the limit for $\mathrm{x}$ (see Fig. 5b). Only after being asked explicitly to do so, she begins to reflect on the realworld situation.

Comparing these two cases, both students have difficulties in integrating the real world into their models. What seems to differ are the possible reasons for these difficulties. For Timothé, this modeling task does not seem to fit into his usual image of mathematics problems. As he is neither used to distinguishing relevant from irrelevant data nor searching for missing information himself, he has difficulties constructing an 
adequate mathematical model. This is evident in his many steps forwards and backwards in Fig. 4, while he tries to construct a real and a mathematical model.

Marie, however, is used to ignoring real-world aspects of a task's context. She tries to apply well-known strategies to "unwrap" the problem and explains: "You know, you had to wangle a bit more... normally, we do integrals all the time, and then you know you've got to solve the problem with integrals". Her focus is on classifying the problem to a certain mathematical topic and not on the adequate description of the real situation. Hence, it is mostly the missing connection to the current topic of her mathematics lessons that make the task so difficult for her. Instead of analysing the real situation, Marie tries to fit her imperfect understanding of the situation into a symbolic representation. This is also evident in her modeling route, where she shows many attempts to mathematize the problem.

Additionally, there seem to be two sorts of real worlds for her: the one in which not everything is perfect, and the reality of a mathematics task, in which one can even assume that light shines around the globe. In Marie's opinion, school mathematics does not produce solutions to authentic problems, because the problems tackled at school are a priori simplified.

Another difference between both students lies in their attitude towards inaccuracy. For Timothé, it is a major flaw of his solution that it is not exact. Even though he can construct a model that fits his mathematical knowledge and gives a close approximation, he values a solution that estimates the arc much higher. Marie accepts without hesitation her approximated solution and reflects more on extra-mathematical exactitude, for example on weather conditions or the dispersion of light in the atmosphere. She even compares her result with her experience with lighthouses, while Timothé reflects more on different mathematical models that could have been used.

\section{Discussion}

\subsection{Possible connection with national differences}

Even though there is a broad variety of modeling processes, the two basic blockages illustrated in this paper seem to be prototypical for both countries. The French students were not familiar with the fact that the context played a more important role for their solution processes than merely to motivate them. The German students seemed to be more used to a real-world context but often applied strategies to "undress" the mathematical content. They were more willing than the French students to accept a simplification of the situation and used less complex mathematical models. For example, the French students often proposed or used trigonometric functions to calculate the arc, instead of its linear approximation (use of Pythagorean theorem: $50 \%$ of the French cases versus $75 \%$ of the German cases). This is probably also due to trigonometry playing a more important role in the French curriculum than in the German. The tendency to blindly apply mathematics without reflecting on the given situation is no new thing (see Baruk, 1989). However, the reason for this behaviour seems to differ between both nations: examples of everyday life are not often used in French mathematics textbooks (Cabassut, 2007; Stölting, 2008), and inner-mathematical, formal justifications play an important role (Knipping, 2003), whereas the German students have accepted socio-mathematical norms that a deeper understanding of the context is not the focus of a mathematical task and can sometimes even hinder the solution of a mathematical problem (Gellert \& Jablonka, 2009). This shows that, even though German mathematics teachers might be more familiar with the 
theory of mathematical modeling as explained above, the German students did not have advantages or fewer problems with the task.

The different approaches to handling the real-world situation are in accordance with the general image of mathematics in upper secondary school in both nations. Some of the French students claimed that they did not know such a task from mathematics. This becomes especially evident in the work from a French student, who judges his mathematical work as "not very mathematical". He stated that "it works in physics, but in maths, you try to avoid arcuscosinus and all that, I do not know, in maths, you are more into exact values or trigonometric formulas and stuff." German students in this sample did not comment on the imprecision but took it as a typical characteristic of an application task. This blockage may also be due to different styles of teaching. Molyneux-Hodgsons, Rojano, Sutherland, and Ursini (1999) find that a more presentational style of teaching seems to be linked to an emphasis on precise answers. Since such a style was quite common in French classrooms a couple of decades ago (Broadfoot, 1999), the tendency to prefer exact values may be a relic of these times.

\subsection{Methodological discussion}

The small-scale study with 30 students presented here cannot provide an exhaustive reflection on and description of what is happening in mathematics classrooms in both countries. The question arises as to whether these differences are due to individual preferences (Maß, 2006, Borromeo Ferri, 2010a, b) or differ systematically between the two countries. Additionally, since the sample is not representative, it is possible that the variation between student processes in one country might be broader than the variety between the two countries. This is especially valid for Germany, where the educational systems are different in each federal state. Therefore, students' blockages cannot be causally attributed to the different historical background. Nevertheless, it seems reasonable to assume that students' modeling routes are related to their national contexts because current styles of mathematics education can be seen as the result of a historical process where different learning opportunities are prepared in relation to predominant teaching styles. Since these learning opportunities highlight different aspects, for example technical competences or mathematical accuracy, it is probable that provably influential factors for modeling, such as self-efficacy (Krawitz \& Schukajlow, 2018) or conceptual knowledge (Chang, Krawitz, Schukajlow, et al., 2019), differ between students from different countries. This mediating relationship should be analysed in further studies.

Additionally, the number of observed students could provide a degree of saturation, as students' difficulties occurred repeatedly (c.f. Table 2). This study thus did not aim at a general comparison between two countries but at the comparison between two educational contexts that are shaped by different traditions and didactical movements. To gain deeper insight into these contexts, not only were student processes video-taped but also data from their respective mathematics lessons and from teachers was collected. The combination of all data should deepen our understanding of how students' individual modeling processes are influenced by external factors.

The think-aloud method for this study made it possible to immediately gain insight into students' thought processes. Of course, even though students were trained in this method, the setting is not a natural one and might have influenced students' processes by encouraging a more thorough meta-cognition. Nevertheless, this method has the advantage that most thought 
processes can be retraced, even those the students would not report afterwards, for example in some sort of learning report.

Furthermore, this kind of inter-cultural study makes it necessary to cope with the different languages. It was possible for students to talk in their mother tongue and to have the same person conducting the experiment in both countries. Because of the collaboration of scholars from both countries, it was possible to transcribe and analyse the videos without having to translate them. This was important for avoiding distortion due to language issues.

Participation in the study was of course voluntary. Also, both schools came from a comparable surrounding, and in both the German and the French sample, there were high-, medium- and low-achievers regarding their mathematics grades. Of course, this does not mean that students were at the same mathematical level, as no standardized test was conducted.

In conclusion, we have seen that the conception of mathematics education often differed throughout history in two neighbouring countries. The study presented in this article has given an example of how students' modeling processes differ and which blockages they encounter. It became evident that students from both nations encountered various blockages that hindered them from solving the task. This speaks for the integration of more and complex modeling tasks into everyday teaching in both countries. Inaccuracy and the question of how to treat missing or superfluous data play a central role in this debate, which differs from formal and pure mathematics. Furthermore, some assumptions about the relationship between students' blockages and the underlying conceptions and teaching traditions in their nations were made. Even though the presented differences cannot be causally attributed to the historical differences, this historical background has certainly shaped how mathematics education is seen and carried out today in both nations and hence influences what opportunities to learn students encounter.

Being aware of this cultural relationship is especially important when constructing or adapting learning aids for mathematical modeling. Even if such aids share a common underlying structure, it might be necessary to adapt them according to the national context so that they may help effectively in overcoming blockages.

Funding Information Open Access funding provided by Projekt DEAL.

\section{Appendix}

\section{Exemplary solution of the lighthouse task}

Remark: This solution can be seen as an example of a student's approach to solving the task. It is not meant to be an ideal solution, as every assumption, mathematical model or solution has to be evaluated not only with regard to student abilities, but also with regard to the extra-mathematical situation. For example, a more complex model does not always have to be the better one. A solution can be evaluated just as well if the student has a sound understanding of the given real-world situation and simplifies it in such a way that he or she is able to construct a sufficiently complex mathematical model, which allows him or her to find a reasonable answer to the starting question. The necessary exactitude of the result for it to be reasonable thereby depends on the formulation of the task and 
understanding of the real-world situation by the student, as well as on the mathematical tools at the student's disposal.

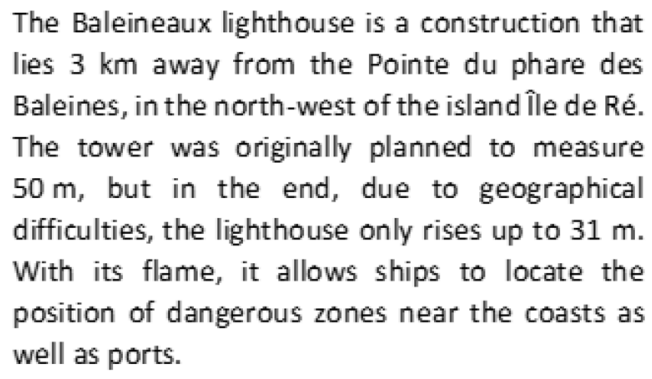

\section{What distance to the coast does a ship still have when it catches sight of the lighthouse's light for the first time?}

https://upload.wikimedia.org/wikipedia/commons/3/31/Baleineaux.jpg

\section{The task}

1. Understanding and simplifying the situation

The task gives information about a lighthouse on the Atlantic coast of France which is located $3 \mathrm{~km}$ away from the coast and measures $31 \mathrm{~m}$. As it is the purpose of such a lighthouse to warn ships about the possibly dangerous coastal area, it is important for the ship's crew to know their distance from the coast when they catch sight of the lighthouse for the first time.

Since the exact distance depends on various factors, like the weather, the height of the ship, etc., but no information about the arriving ship is given, it seems reasonable to search for a rough estimation. Therefore, some simplifying assumptions can be made:

- There are ideal weather conditions;

- The height of the ship can be ignored;

- The light is radiated on top of the lighthouse, thus located $31 \mathrm{~m}$ above the sea.

- The maximum distance is limited by the earth's curvature. To be able to work with this curvature by applying school mathematics, the earth is assumed to be a perfect sphere with a radius of $6371 \mathrm{~km}$.

2. Mathematizing the situation and working mathematically

All these assumptions can be converted into the following mathematical model: it is sufficient to use a two-dimensional representation of the situation, which is a cross-section of the earth and the lighthouse (see Appendix Fig. 8). In this representation, it becomes obvious that the maximum distance between the ship (catching sight of the light) and the lighthouse is equivalent to the distance between the point of tangency of a tangent of the circle passing through the top of the lighthouse and the foot of the lighthouse.

Since the tangent line and the radius at the tangency point are right-angled, trigonometric theorems are applicable. 


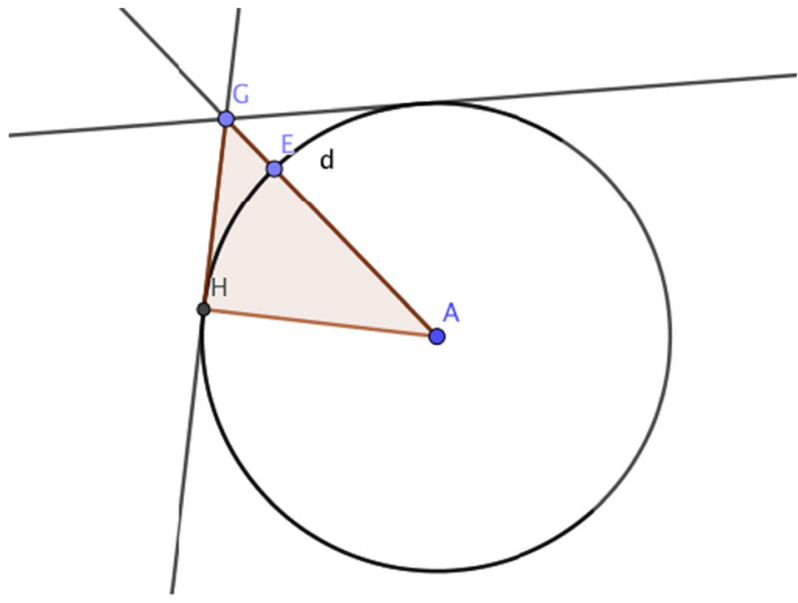

Fig. 8 Two-dimensional representation of the situation (not to scale). The circle $\mathrm{d}$ represents the earth, section GE represents the lighthouse, the tangent GH represents the ray of light and the point $\mathrm{H}$, the position of the boat. Thus, the distance HE has to be calculated or approximated to answer the question

The easiest way to approximate the distance HE is to calculate the linear distance by applying the Pythagorean theorem twice: Since EA $=\mathrm{HA}=6371[\mathrm{~km}]$ and $\mathrm{GE}=31[\mathrm{~m}]$, it follows that

$$
\mathrm{HG}=\sqrt{G A^{2}-H A^{2}}=\sqrt{6371.031^{2}-6371^{2}}=\sqrt{395.003} \approx 19.875[\mathrm{~km}] .
$$

Applying the Pythagorean theorem a second time yields

$$
\mathrm{HE}=\sqrt{G H^{2}-G E^{2}}=\sqrt{395.003-0,031^{2}}=\sqrt{394.972} \approx 19,874[\mathrm{~km}] .
$$

(Remark: Since the lighthouse is very small in relation to the earth's radius, the first application of the Pythagorean theorem already gives a good approximation of the distance.)

Another possibility is to determine the curved distance HE by using the definition of cosine: If the angle between HA and GA is called $\alpha$, it is known that

$$
\alpha=\arccos \left(\frac{H A}{G A}\right)=\arccos \frac{6371}{6371.031} \text { and } \mathrm{HE}=\frac{\alpha}{360} \cdot 2 \cdot \pi \cdot 6371 \approx 19,874[\mathrm{~km}] .
$$

3. Interpreting and validating the result

Both calculations indicate that the ship is approximately $20 \mathrm{~km}$ from to the lighthouse, when it catches sight of its light for the first time. Since the lighthouse is not located on the coast, but $3 \mathrm{~km}$ in front of it, the ship can have a maximal distance of $23 \mathrm{~km}$ to the coast, depending from which side the ship arrives. This distance seems to be reasonable, as it leaves enough time for the ship's crew to react accordingly and to adjust their course.

Nevertheless, the assumption that the height of the ship can be ignored may have severe consequences for the distance measurement. The higher the ship, the greater is the maximum distance to the lighthouse. This information can be integrated into the model as Appendix Fig. 9 shows. With 


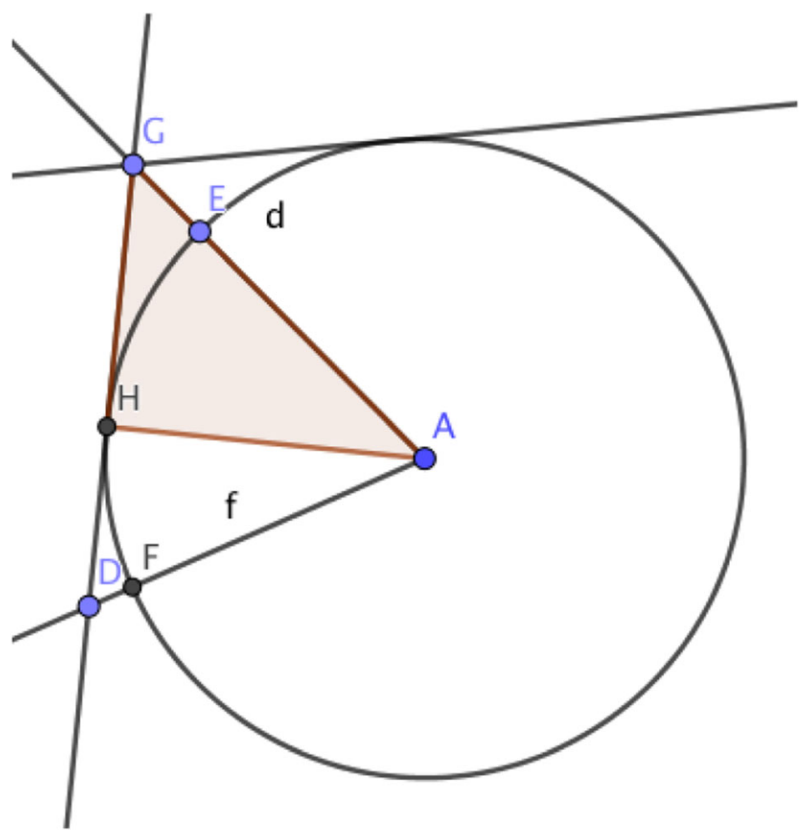

Fig. 9 Extension of Fig. 1: F representing the position of the ship, DF representing the height of the ship and the seaman

this model, various heights of the ship, represented by section DF, can be tested and the distance FE can be compared. But these reflexions go far beyond what is expected for the given task.

Open Access This article is licensed under a Creative Commons Attribution 4.0 International License, which permits use, sharing, adaptation, distribution and reproduction in any medium or format, as long as you give appropriate credit to the original author(s) and the source, provide a link to the Creative Commons licence, and indicate if changes were made. The images or other third party material in this article are included in the article's Creative Commons licence, unless indicated otherwise in a credit line to the material. If material is not included in the article's Creative Commons licence and your intended use is not permitted by statutory regulation or exceeds the permitted use, you will need to obtain permission directly from the copyright holder. To view a copy of this licence, visit http://creativecommons.org/licenses/by/4.0/.

\section{References}

Baruk, S. (1989). Wie alt ist der Kapitän? Über den Irrtum in der Mathematik. Basel, Switzerland: Birkhäuser. Blum, W. (1985). Anwendungsorientierter Mathematikunterricht in der didaktischen Diskussion. Mathematische Semesterberichte, 32(2), 195-232.

Blum, W. (2007). Mathematisches Modellieren - zu schwer für Schüler und Lehrer? In E. Vásárhely (Ed.), Beiträge zum Mathematikunterricht (pp. 3-12). Hildesheim, Germany: Franzbecker.

Blum, W. (2011). Can modelling be taught and learnt? Some answers from empirical research. In G. Kaiser et al. (Eds.), Trends in teaching and learning of mathematical modelling (ICTMA 14) (pp. 15-30). Dordrecht, the Netherlands: Springer.

Blum, W. (2015). Quality teaching of mathematical modelling: What do we know, what can we do? In S. J. Cho (Ed.), The proceedings of the 12th international congress on mathematical education (pp. 73-96). Cham, Switzerland: Springer International Publishing.

Blum, W., \& Leiß, D. (2007). How do students and teachers deal with mathematical modelling problems? The example sugarloaf and the DISUM project. In C. Haines, P. L. Galbraith, W. Blum, \& S. Khan (Eds.), 
Mathematical modelling (ICTMA 12). Education, engineering and economics (pp. 222-231). Chichester, UK: Horwood.

BOEN (Bulletin official de l'Education Nationale). (2015). Programmes d'enseignement du cycle des apprentissages fondamentaux (cycle 2), du cycle de consolidation (cycle 3) et du cycle des approfondissements (cycle 4). Bulletin official spécial $\mathrm{n}^{\circ} 10$.

Borromeo Ferri, R. (2006). Theoretical and empirical different of phases in the modelling process. ZDM Mathematics Education, 38(2), 86-95.

Borromeo Ferri, R. (2010a). On the influence of mathematical thinking styles on learners' modelling behavior. Journal für Mathematik-Didaktik, 31(1), 86-95.

Borromeo Ferri, R. (2010b). On the influence of mathematical thinking styles on learners' modelling behaviour. Journal für Mathematikdidaktik, 31(1), 99-118.

Broadfoot, P. (1999). Comparative research on pupil achievement: In search of validity, reliability and utility. In R. Alexander, P. Broadfoot, \& D. Phillips (Eds.), Learning from comparing: New directions in comparative educational research. Volume 1: Contexts, classrooms and outcomes (pp. 237-259). Oxford, UK: Symposium Book.

Cabassut, R. (2007). Examples of comparative methods in the teaching of mathematics in France and in Germany. In Proceedings of 5th CERME (pp. 2423-2432). Cyprus: Larnaca.

Cai, J., Mok, I., Reddy, V., \& Stacey, K. (2017). International comparative studies in mathematics: Lessons and future directions for improving students' learning. In G. Kaiser (Ed.), Proceedings of the 13th International Congress on Mathematical Education (pp. 79-99). Springer International Publishing.

CCSS-M. (2010). Common Core State Standards for Mathematics. Washington, D.C.: National Governors Association Centre for Best Practices.

Chang, Y. P., Krawitz, J., Schukajlow, S., et al. (2019). Comparing German and Taiwanese secondary school students' knowledge in solving mathematical modelling tasks requiring their assumptions. ZDM Mathematics Education. https://doi.org/10.1007/s11858-019-01090-4

Galbraith, P., \& Stillman, G. (2006). A framework for identifying student blockages during transitions in the modelling process. ZDM, 38(2), 143-162.

Gellert, U., \& Jablonka, E. (2009). "I am not talking about reality": Word problems and the intricacies of producing legitimate text. In L. Verschaffel, B. Greer, W. van Dooren, \& S. Mukhopadhyay (Eds.), Words and worlds: modelling verbal descriptions of situations (pp. 39-53). Rotterdam, the Netherlands: Sense.

Gispert, H., \& Schubring, G. (2011). Societal, structural and conceptual changes in mathematics teaching: Reform processes in France and Germany over the twentieth century and the international dynamics. Science in Context, 24(1), 73-106.

Grangeat, M. (Ed.). (2011). Les démarches d'investigation dans l'enseignement scientifique. Lyon, France: Ecole Normale Supérieure.

Greefrath, G. (2011). Modelling problems and digital tools in German centralised examinations. In M. Pythlak, E. Swoboda, \& T. Rowland (Eds.), Seventh Congress of the European Society for Research in Mathematics Education (pp. 957-963). Poland: Rzeszów.

Greefrath, G., \& Vorhölter, K. (2016). Teaching and Learning Mathematical Modelling: Approaches and Developments from German Speaking Countries [ICME-13 topical survey]. Cham, Switzerland: Springer Open.

Gueudet, G., Bueno-Ravel, L., Modeste, S., \& Trouche, L. (2017). Curriculum in France: A National Frame in transition. In D. Thompson, M. A. Huntley, \& C. Suurtamm (Eds.), International perspectives on mathematics curriculum (pp. 41-70). Charlotte, NC: International Age Publishing.

Henn, H.-W., \& Kaiser, G. (2001). Mathematik — ein polarisierendes Schulfach. Zeitschrift für Erziehungswissenschaft, 4(3), 359-380.

Kahane, J.-P. (2002). L'enseignement des sciences mathématiques. Paris, France: Odile Jacob.

Kaiser, G. (2002). Educational philosophies and their influence on mathematics education - An ethnographic study in English and German mathematics classrooms. ZDM Mathematics Education, 34(6), 241-257.

Kaiser, G., \& Sriraman, B. (2006). A global survey of international perspectives on modelling in mathematics education. Zentralblatt der Mathematikidaktik, 38(38), 302-310.

Kaiser-Meßmer, G. (1986). Anwendungen im Mathematikunterricht. Bad Salzdetfurth, Germany: Franzbecker.

Klein, F. (1907). Vorträge über den mathematischen Unterricht an den höheren Schulen. Leipzig, Germany: Teubner.

KMK (Kultusminister-Konferenz). (2003). Bildungsstandards im Fach Mathematik für den Mittleren Schulabschluss. Beschluss vom, 4(12), 2003.

Knipping, C. (2003). Learning from comparing. A review and reflection on qualitative oriented comparisons of teaching and learning mathematics in different countries. ZDM Mathematics Education, 35(6), 282-293. 
Krawitz, J., \& Schukajlow, S. (2018). Do students value modelling problems, and are they confident they can solve such problems? Value and self-efficacy for modelling, word, and intra-mathematical problems. ZDM Mathematics Education, 50, 143-157.

Kühnel, J. (1916). Neubau des Rechenunterrichts. Leipzig: Klinkhardt.

Leiß, D., Schukajlow, S., Blum, W., Messner, R., \& Pekrun, R. (2010). The role of the situation model in mathematical modelling - task analyses, student competencies and teacher interventions. Journal für Mathematikdidaktik, 31, 119-141.

Maaß, K. (2006). What are modelling competencies? ZDM Mathematics Education, 38(2), 113-142.

Mayring, P., \& Fenzl, T. (2014). Qualitative Inhaltsanalyse. In N. Baur \& J. Blasius (Eds.), Handbuch Methoden der empirischen Sozialforschung. Wiesbaden, Germany: Springer VS.

McLean, M. (1990). Britain and a single market Europe. London, UK: Kogan Page.

Molyneux-Hodgsons, S., Rojano, T., Sutherland, R., \& Ursini, S. (1999). Mathematical modelling: The interaction of culture and practice. Educational Studies in Mathematics, 39, 167-183.

Moyer, J. C., Robison, V., \& Cai, J. (2018). Attitudes of high-school students taught using traditional and reform mathematics curricula in middle school: A retrospective analysis. Educational Studies in Mathematics, 98(2), 15-134.

Pepin, B. (2002). Different cultures, different meanings, different teaching. In L. Haggarty (Ed.), Teaching mathematics in secondary schools (pp. 245-258). London, UK: Routledge.

Schaap, S., Vos, P., \& Goedhart, M. (2011). Students overcoming blockaghes while building a mathematical model: Exploring a framework. In G. Kaiser, W. Blum, R. Borromeo Ferri, \& G. Stillmann (Eds.), Trends in teaching and learning of mathematical modeling (pp. 137-146). Dordrecht, the Netherlands: Springer.

Schukajlow, S. (2006). Schüler-Schwierigkeiten beim Lösen von Modellierungsaufgaben - Ergebnisse aus dem DISUM-Projekt. Beiträge zum Mathematikunterricht., 493-496.

Schukajlow, S., Kaiser, \& G. Stillman, G. (2018) Empirical research on teaching and learning of mathematical modelling: a survey on the current state-of-the-art. ZDM 50(1-2):5-18.

Stillman, G. (2012). Applications and modelling research in secondary classrooms: What have we learnt? In Preproceedings of ICME12. Korea: Seoul.

Stillman, G., Brown, J., \& Galbraith, P. (2010). Identifying challenges within transition phases of mathematical modelling activities at year 9. In R. Lesh, P. Galbraith, C. Haines, \& A. Hurford (Eds.), Modeling students' mathematical modeling competencies (pp. 385-398). New York, NY: Springer.

Stölting, P. (2008). Die Entwicklung funktionalen Denkens in der Sekundarstufe I vergleichende Analysen und empirische Studien zum Mathematikunterricht in Deutschland und Frankreich. Dissertation, Universität Regensburg.

Trouche, L. (2017). Didactics of Mathematics: Concepts, Roots, Interactions and Dynamics from France. In J. Monaghan, L. Trouche, \& J. M. Borwein (Eds.), Tools and Mathematics. Switzerland: Springer.

Publisher's note Springer Nature remains neutral with regard to jurisdictional claims in published maps and institutional affiliations. 